\title{
REVIEW
}

\section{The role of leukaemia inhibitory factor in the establishment of pregnancy}

\author{
D Vogiagis and L A Salamonsen
}

Prince Henry's Institute of Medical Research, PO Box 5152, Clayton, Victoria 3168, Australia

(Requests for offprints should be addressed to D Vogiagis, Monash University Medical School, Department of Surgery, Alfred Hospital, Melbourne, Victoria 3181, Australia)

\begin{abstract}
Leukaemia inhibitory factor (LIF) is a pleiotrophic cytokine required for blastocyst implantation in mice. Uterine expression of LIF and that of its receptors has been demonstrated in a number of mammalian species indicating that LIF may have widespread importance in the establishment of pregnancy. The variations in the reaction of the uterus in preparation for and during implantation are considerable between species and understanding the differences and similarities assists in the interpretation of how this cytokine functions. Recent studies suggest that
\end{abstract}

reduced endometrial LIF contributes to human infertility. Studies also demonstrate a potential role in placentation and fetal development. Thus, LIF has become an important cytokine warranting further investigation in the human. It is anticipated that when the mechanisms underlying normal embryonic and endometrial development are elucidated, fertility and infertility will be more precisely understood and hence able to be effectively controlled.

Journal of Endocrinology (1999) 160, 181-190

\section{Introduction}

Implantation, the process by which the blastocyst attaches itself in the uterus and the trophectoderm develops an intimate relationship with the cells of the endometrium, involves a complex sequence of signalling events crucial in the establishment of pregnancy. A large number of molecular mediators have been identified and are postulated to be involved in this interaction (Tabibzadeh 1991, Guilbert et al. 1993, Giudice \& Saleh 1994, Stewart \& Cullinan 1997, Senturk \& Arici 1998). It is clear that ovarian hormones initiate the process; however, the details of the events and components crucial to early pregnancy remain to be defined. In the human, as many as two-thirds of pregnancies are estimated to fail in healthy women attempting to conceive (Smart et al. 1982). An even higher amount of embryonic wastage occurs following in vitro fertilisation and embryo transfer (Liu et al. 1988). The majority of these losses occur prior to or during implantation and progress towards improving early pregnancy success rates relies upon a better understanding of the underlying mechanisms. Leukaemia inhibitory factor (LIF) is one cytokine which appears to be critically involved in embryonic development and implantation. This review will focus on the current knowledge of LIF in the reproductive tract of different mammalian species. Such comparisons have led to a better understanding of the role that LIF plays in the establishment of pregnancy.

\section{Background and history of leukaemia inhibitory factor}

The pleiotrophic cytokine, LIF, was initially identified by its ability to induce the macrophage differentiation of the myeloid leukaemic cell line M1 (Tomida et al. 1984, Hilton et al. 1988a,b). LIF has been separately identified and named by several laboratories due to its varied biological activities (Gough et al. 1992). The name under which the cDNA and genomic clones were originally isolated is the most commonly used (Gearing et al. 1987, 1988). Interestingly, the pleiotrophic effects of LIF in many physiological systems include proliferation, differentiation and cell survival (for reviews see Hilton 1992, Metcalf 1992), all of which are associated with blastocyst development and implantation.

LIF exerts a broad range of effects on diverse cell types and many of these actions can be mimicked by related cytokines, in particular interleukin 6 (IL-6), oncostatin M (OSM), ciliary neurotrophic factor (CNTF) and cardiotrophin-1 (CT-1). This overlap occurs because such factors can interact with each others' receptors to varying 


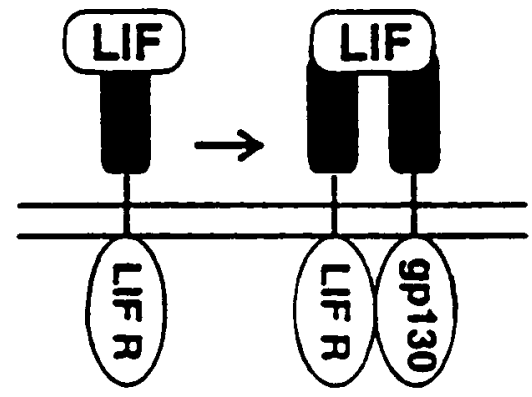

Figure 1 Model of the formation of the LIF receptor complex. The schematic diagram illustrates the events leading to ligand-induced signalling (the cell membrane is represented by a bar, with the extracellular region above and the intracellular region below). LIF binds to LIFR and then gp130 is bound. This heterodimerisation results in signal transduction (modified from Davis et al. 1993).

degrees (Gearing et al. 1992, Ip et al. 1992, Murakami et al. 1993, Pennica et al. 1995). Yet some of the functions exhibited by LIF cannot be compensated for by other cytokines. LIF was the first protein identified to influence the differentiation of cells derived from the early mouse embryo (Smith et al. 1988, Williams et al. 1988) and has now been shown to be required for blastocyst implantation in mice (Stewart et al. 1992).

The pleiotrophic and redundant functioning of cytokines such as LIF has been partly explained since the molecular characterisation of the cytokine receptor systems. The activation of the LIF receptor (LIFR) complex (Fig. 1) requires heterodimerisation of the two low affinity components LIFR and gp130 (Gearing et al. 1991, Ip et al. 1992, Taga \& Kishimoto 1992) and this combination generates a high affinity binding site (Gearing et al. 1992). Interestingly, the LIFR and gp130 transmembrane proteins have also been shown to serve as receptors for OSM, CNTF and CT-1, while an active IL-6 receptor complex requires gp130 (Murakami et al. 1993). The shared activities of the LIF receptor family suggest that other members may also be important in regulating blastocyst development and implantation.

The low affinity LIF receptor was first characterised by Gearing et al. (1991) and designated LIFR. LIFR is also referred to as LIF receptor $\alpha$-chain (Nicola \& Metcalf 1991, Zhang et al. 1997) and LIFR $\beta$ (Stahl \& Yancopoulos 1993).

\section{A comparative view of early pregnancy in different mammalian species}

Uterine expression of LIF at the time of blastocyst implantation or expected implantation has been described in a number of species including mice, humans and sheep. There are considerable species variations in the reaction of the uterus in preparation for and during implantation (reviewed in Wooding \& Flint 1994) and understanding the differences and similarities assists in the interpretation of how LIF and other mediators function (Table 1).

For implantation to occur, the blastocyst must first lose the zona pellucida to allow intimate adhesion between the trophectoderm and the uterine epithelial surface. In the mouse, the blastocyst both enters the uterine horn and hatches from the zona pellucida on the fourth day of gestation, implanting on the uterine wall later that same day (Finn \& McLaren 1967, Orsini \& McLaren 1967). In the human, the morula enters the uterus, transforms to a blastocyst and loses its zona pellucida by $5-6$ days after ovulation (Falck Larson 1980). The first attachment of the human blastocyst to the human epithelium occurs at approximately 6-7 days after ovulation (Hearn 1980). While the sheep embryo enters the uterus about 5 days after ovulation, there is a characteristically long intrauterine blastocyst development before implantation, with hatching (day 9) and implantation (day 16) occurring about 7-8 days apart (Rowson \& Moor 1966). Thus the

Table 1 Comparison of early pregnancy in mice, humans and sheep

\begin{tabular}{|c|c|c|c|}
\hline & Mouse & Human & Sheep \\
\hline Type of cycle & Oestrous & Menstrual & Oestrous \\
\hline Length of cycle (days) & 4 & 28 & 17 \\
\hline Type of uterus & Duplex & Simplex & Bicornuate \\
\hline Day of embryo entry into uterus & 4 & $5-6$ & 5 \\
\hline $\begin{array}{l}\text { Stage of development } \\
\text { upon entry }\end{array}$ & Blastocyst & Morula & Morula \\
\hline Day of loss of zona pellucida & 4 & $5-6$ & 9 \\
\hline Day of implantation & $4 \cdot 5$ & $6-7$ & 16 \\
\hline Type of implantation & $\begin{array}{l}\text { Interstitial, } \\
\text { antimesometrial }\end{array}$ & Interstitial & Superficial \\
\hline $\begin{array}{l}\text { Type of fetomaternal } \\
\text { cellular interaction }\end{array}$ & Displacement & Intrusion & Fusion \\
\hline Placentation & Haemochorial & Haemochorial & Synepitheliochorial \\
\hline Decidual development & Extensive & Considerable & None \\
\hline
\end{tabular}

Mice and sheep, day $0=$ day of oestrus; humans, day $0=$ day of ovulation. 
intrauterine environment is likely to assume different importance in diverse species depending on the extent of blastocyst development within that environment.

Mammals also exert control over trophoblast invasion to varying degrees. In humans and mice, a haemochorial placenta is formed and there is invasion of trophoblast through the epithelium and deep into the stroma. In the mouse this invasion is accompanied by the complete death and delamination of the uterine epithelium (Enders $e t$ al. 1980) whereas in the human, the trophectoderm intrudes through the uterine epithelium and the blastocyst passes through the endometrium (Aplin 1991). In species with invasive haemochorial placentation the uterus responds to an implanting blastocyst by undergoing extensive modifications that result in the transformation of the endometrium into the decidua, while in ungulates such as the sheep in which little invasion occurs, attachment of the trophoblast to the endometrium results in a superficial form of implantation with the formation of a synepitheliochorial placenta (Perry 1981).

\section{Role of LIF on the embryo}

A role for LIF in the regulation and the pre-implantation development of the mammalian embryo was first proposed after studies were performed in the mouse. The observation that recombinant LIF inhibited murine embryonic stem cell differentiation in vitro (Smith et al. 1988, Williams et al. 1988), indicated that LIF may have a role in the growth and development of early mouse embryos. Additionally, LIF mRNA is expressed in mouse preimplantation embryos at stages from the fertilised egg to the blastocyst (Conquet \& Brulet 1990, Murray et al. 1990). Mouse blastocysts cultured in the presence of LIF have a greater mass of trophectoderm compared with control blastocysts (Roberston et al. 1991). In the sheep, recombinant human LIF improves the development of ovine embryos in culture (Fry et al. 1992) and when human embryos are cultured with LIF an enhancement of blastocyst formation rates occur (Dunglison et al. 1996). These data suggest that LIF may be one of many factors involved in improving embryo viability in vitro.

\section{Expression and localisation in uterine tissue}

In the mouse uterus, LIF is transiently expressed with a distinct peak of both mRNA and protein occurring at the time of blastocyst implantation in the endometrial epithelium (day 4; Bhatt et al. 1991, Shen \& Leder 1992) and at oestrus concurrent with ovulation (Shen \& Leder 1992). This expression is paralleled in pseudopregnant mice indicating that LIF may be maternally controlled rather than being induced by a signal originating from the embryo (Bhatt et al. 1991, Shen \& Leder 1992). Further- more, LIF appears to be regulated by oestradiol since the two peaks of LIF expression coincide with physiologically elevated levels of oestrogen or can be induced by an injection of oestradiol-17 $\beta$ in females undergoing either naturally or experimentally induced delayed implantation (Bhatt et al. 1991).

The expression of LIF has been demonstrated in the uterus of a variety of mammals. In most species LIF expression increases around the time of blastocyst implantation or expected implantation (Fig. 2). In uterine biopsy samples from women of proven fertility, LIF mRNA expression is observed during the secretory/postovulatory phases (days 18-28) of the menstrual cycle (CharnockJones et al. 1994, Kojima et al. 1994, Arici et al. 1995, Cullinan et al. 1996, Vogiagis et al. 1996). LIF mRNA and protein are localised to the uterine glandular and luminal epithelium using in situ hybridisation and immunohistochemistry respectively (Cullinan et al. 1996, Vogiagis et al. 1996), while immunoreactive LIF is also observed in the stroma (Cameron et al. 1996, Vogiagis et al. 1996, Gemzell Danielsson et al. 1997). In endometrium of rhesus monkeys, LIF transcripts as detected by reverse transcriptionPCR, were elevated during the secretory phase (Ace \& Okulicz 1995) in accordance with data from the human. By contrast, in the sheep uterus, endometrial LIF mRNA expression remains relatively constant throughout the oestrous cycle and is also present during early pregnancy with the highest expression observed at the time of (days 16-20) implantation and placentation (Vogiagis et al. 1997a). Immunoreactive LIF is localised in rabbit endometrial epithelium and myometrium at high levels on day 5 of pregnancy and remains at high levels until blastocyst implantation occurs on day 7 (Yang et al. 1994). Thus, endometrial LIF expression is elevated during early pregnancy in all species investigated, but is not always confined exclusively to the day of blastocyst implantation. Rather, LIF remains raised throughout the postovulatory phase in many species and this may reflect a need for this cytokine throughout preimplantation blastocyst development.

The different temporal relationship of endometrial LIF expression across the ovarian cycle in a variety of species suggests different steroidal regulation. In the mouse LIF appears to be regulated by oestradiol (Bhatt et al. 1991, Yang et al. 1996) and there is a close link between the surge of oestradiol required for implantation and the burst of LIF expression (Bhatt et al. 1991), whereas in the rabbit, uterus LIF expression appears to be controlled by progesterone (Yang et al. 1996). Likewise, in human endometrium LIF expression is maximal during the postovulatory phase when the endometrium is under the influence of progesterone. In support of progesterone as a regulator of LIF expression in fertile women, treatment with the progesterone receptor antagonist mifepristone (RU486) immediately post ovulation reduces endometrial glandular immunolocalisation of LIF at the expected time 

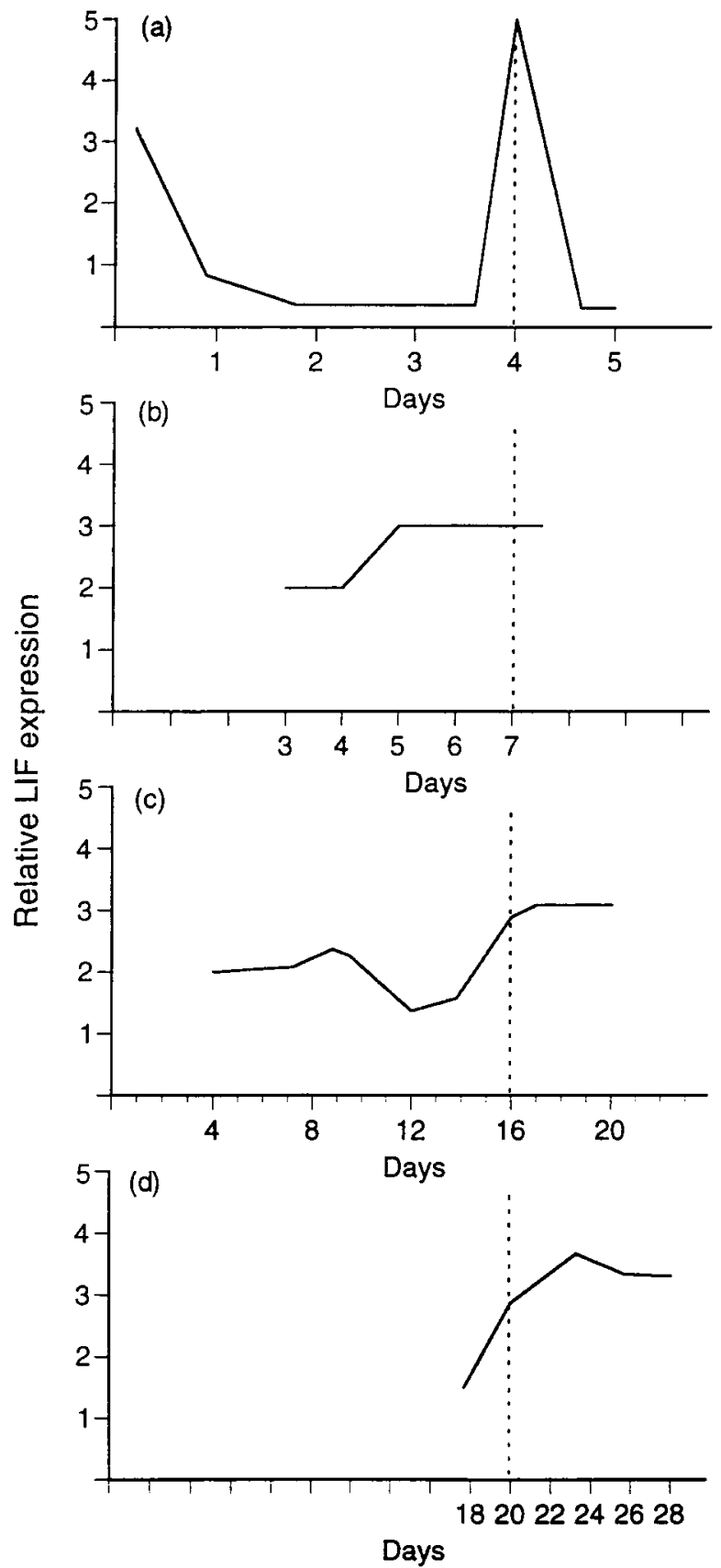

Figure 2 Diagrammatic representation of endometrial LIF expression (mRNA or protein) during early pregnancy in: (a) mouse, mRNA; (b) rabbit, protein; (c) sheep, mRNA or (d) during the menstrual cycle in human, mRNA. The broken line represents the day of blastocyst implantation or expected implantation. From (a) Stewart (1994); (b) Yang et al. (1994); (c) Vogiagis et al. (1997a); (d) Vogiagis et al. (1996), Cullinan et al. (1996).

of implantation (Gemzell Danielsson et al. 1997). In ovariectomised ewes treated with oestradiol, there is a reduction in endometrial immunoreactive LIF compared with animals treated with oestrogen and progesterone (Vogiagis et al. 1997a). Thus, in species other than the mouse, there is no nidatory oestradiol surge and this hormone is not responsible for endometrial LIF expression. Progesterone, the dominant hormone at implantation in most species may regulate LIF expression.

\section{LIF during blastocyst implantation and early pregnancy}

Successful blastocyst implantation in mice involves an absolute requirement for LIF, as demonstrated by gene inactivation experiments (Stewart et al. 1992, Escary et al. 1993). Female mice with no functional LIF gene (LIF-/-), when mated with wild-type or LIF-/- males were found to have normal blastocysts which failed to implant. Such blastocysts could be transplanted to wild-type recipient females where normal implantation and development occurred. Furthermore, provision of recombinant LIF to LIF -/- females revealed that mice had observable implantation sites, while histological examination showed that a decidual response was occurring with embryos undergoing implantation. These data suggested that LIF is involved in the regulation of implantation and that in the absence of LIF, the mouse embryo can develop normally only to the blastocyst stage (Stewart et al. 1992).

In the mouse, it has been suggested that endometrial epithelial-derived LIF acts in a paracrine manner on the embryo and/or as an autocrine regulator of endometrial epithelium to allow implantation (Stewart 1994). The targeted disruption of the LIFR or gp130 gene led to embryonic lethality with mice dying shortly after or during gestation (Ware et al. 1995, Yoshida et al. 1996). The demonstration that both LIFR -/- and gp130 -/embryos undergo normal implantation suggests that epithelial-derived LIF does not act directly via the blastocyst to allow implantation. Furthermore, embryos can develop normally to the blastocyst stage in LIF-deficient females (Stewart et al. 1992). Thus, in the mouse, it appears most likely that LIF may regulate implantation by acting on the uterine epithelium in an autocrine/paracrine manner, preparing the uterus for the implanting embryo, or alternatively LIF may have some indirect effect on the embryo.

Gene knockout experiments are limited to studies in the mouse; however, in pregnant ewes the in vivo role of LIF during the extended period of blastocyst development prior to implantation has been investigated (Vogiagis et al. 1997b). In this study pregnant ewes were passively immunised against LIF in an attempt temporarily to reduce or block the amount of LIF available to target cell receptors of the uterus and/or embryo during early pregnancy. Despite the detection of biologically active LIF antibodies in the uterine lumen prior to implantation, passive immunisation did not completely prevent ewes from 
becoming pregnant, although a 33.5\% decrease in pregnancy rate occurred compared with control animals. These data suggest that LIF may be facilitatory not obligatory for embryo development and implantation in sheep, although it is possible that the actions of uterine LIF were not completely blocked by anti-LIF in some animals.

The biological actions of endometrial LIF in the human are as yet unknown. LIF of endometrial origin may function in the same way as that in the mouse since LIF transcripts and protein are similarly localised in human endometrial glands (Charnock-Jones et al. 1994, Cullinan et al. 1996, Vogiagis et al. 1996) which synthesise and secrete proteins into the uterine lumen. LIF has been detected in uterine flushings during the time of expected implantation in fertile women (Laird et al. 1997), while blastocysts produced by in vitro fertilisation and cultured to the pre-implantation stage exhibit LIFR transcripts (Charnock-Jones et al. 1994). In the uterus LIFR transcripts are restricted to the luminal epithelium during the proliferative and early secretory phases, with gp130 mRNA occurring in both the luminal and glandular epithelium throughout the menstrual cycle (Cullinan et al. 1996). These studies indicate that in the human LIF may provide paracrine signals to both embryonic tissues and uterine epithelium during implantation (Fig. 3).

The direction of LIF secretion (apical or basal, Fig. 3) from the polarised uterine epithelium has not been explored although its detection in human uterine washings (Laird et al. 1997) suggests that it is released at least apically from endometrial glands. Should it be released by-directionally, actions on uterine stroma could also be postulated. Indeed, in vitro LIF stimulates proliferation of endometrial stromal fibroblasts (Salamonsen et al. 1997). Endometrial stroma also contains migratory cells of lymphoid origin including macrophages, neutrophils, eosinophils and mast cells (reviewed in Salamonsen \& Woolley 1996) and the possibility of endometrial LIF acting on these cells also needs to be considered.

There are suggestions that defective LIF expression may contribute to human infertility. LIF can be measured in uterine flushings obtained from normal fertile women (Laird et al. 1997) coincident with uterine LIF expression during the mid-late secretory phases of the menstrual cycle (Charnock-Jones et al. 1994, Kojima et al. 1994, Arici et al. 1995, Cullinan et al. 1996, Vogiagis et al. 1996). However the concentration of LIF in flushings obtained from women with unexplained infertility was significantly lower (at luteinizing hormone day 10/late secretory phase) than in those obtained from normal women at the same time (Laird et al. 1997). These results support those of Delage et al. (1995) and Hambartsoumian (1998), who showed that cultured endometrial explant tissue from infertile women produced less LIF than tissue obtained from fertile women and suggest that decreased LIF expression around the time of expected implantation may contribute to early pregnancy failure. Thus, administration of LIF to infertile women during the early-mid secretory phases may increase their chances of successful implantation.

\section{A role for LIF in decidualisation and placentation}

In species with invasive haemochorial placentation, the uterus responds to an implanting blastocyst by undergoing extensive modifications that result in the transformation of the endometrium into the decidua (Wooding \& Flint 1994). In the mouse and rat, decidualisation can also be triggered in hormonally primed uteri (oestrogen plus progesterone) by artificial stimuli (e.g. an oil drop). The deciduoma, as it is known, appears very similar to the decidua of normal pregnancy (De Feco 1967, Parr \& Parr 1989). Stewart (1994) showed that the injection of paraffin oil to LIF -/- mice mated to vasectomised males did not result in a decidual response, whereas heterozygous control mice did respond. Thus unsuccessful implantation exhibited by LIF-/- females may directly result from an impaired ability of the uterus to undergo a decidual response.

The human uterus, unlike that of the mouse, spontaneously undergoes decidualisation during the later part of the menstrual cycle in the absence of a conceptus and in response to progesterone (Finn 1986); whether LIF has a role in this process is not yet known. However, the expression of uterine LIF during the late secretory phase of the cycle in the human may be related to a role in decidualisation. Interestingly, no decidual reaction occurs in the sheep, as it is characterised by a synepitheliochorial placenta (Wooding \& Flint 1994), yet uterine LIF is expressed until well after blastocyst implantation (Vogiagis et al. 1997a). The demonstrated expression of LIF, LIFR and gp130 in first trimester decidua and the regulation of LIF by decidual cytokines in vitro (Sawai et al. 1997) further suggest a role for LIF in decidual cell function. However, in vitro stimulation of decidual cells by LIF does not influence their proliferation (Sawai et al. 1997).

LIF may also be important during placentation and subsequent fetal development. A potential role for LIF in placentation was first suggested when LIFR was cloned from a human placental cDNA library (Gearing et al. 1991) and this was further highlighted when normal placentation was disrupted in mouse LIFR -/- embryos (Ware et al. 1995). Preliminary studies have also indicated that the addition of recombinant LIF to human first trimester trophoblast or term placentae cytotrophoblast cultures may regulate chorionic gonadotrophin (Sawai et al. 1995, Nachtigall et al. 1996) which is produced by the trophoblast to ensure the maternal recognition of pregnancy (Hearn et al. 1991). Furthermore, exposure of cultured cytotrophoblasts to LIF-significantly increased the expression of oncofetal fibronectin which appears to mediate the attachment of the placenta to the uterus (Nachtigall et al. 1996). 


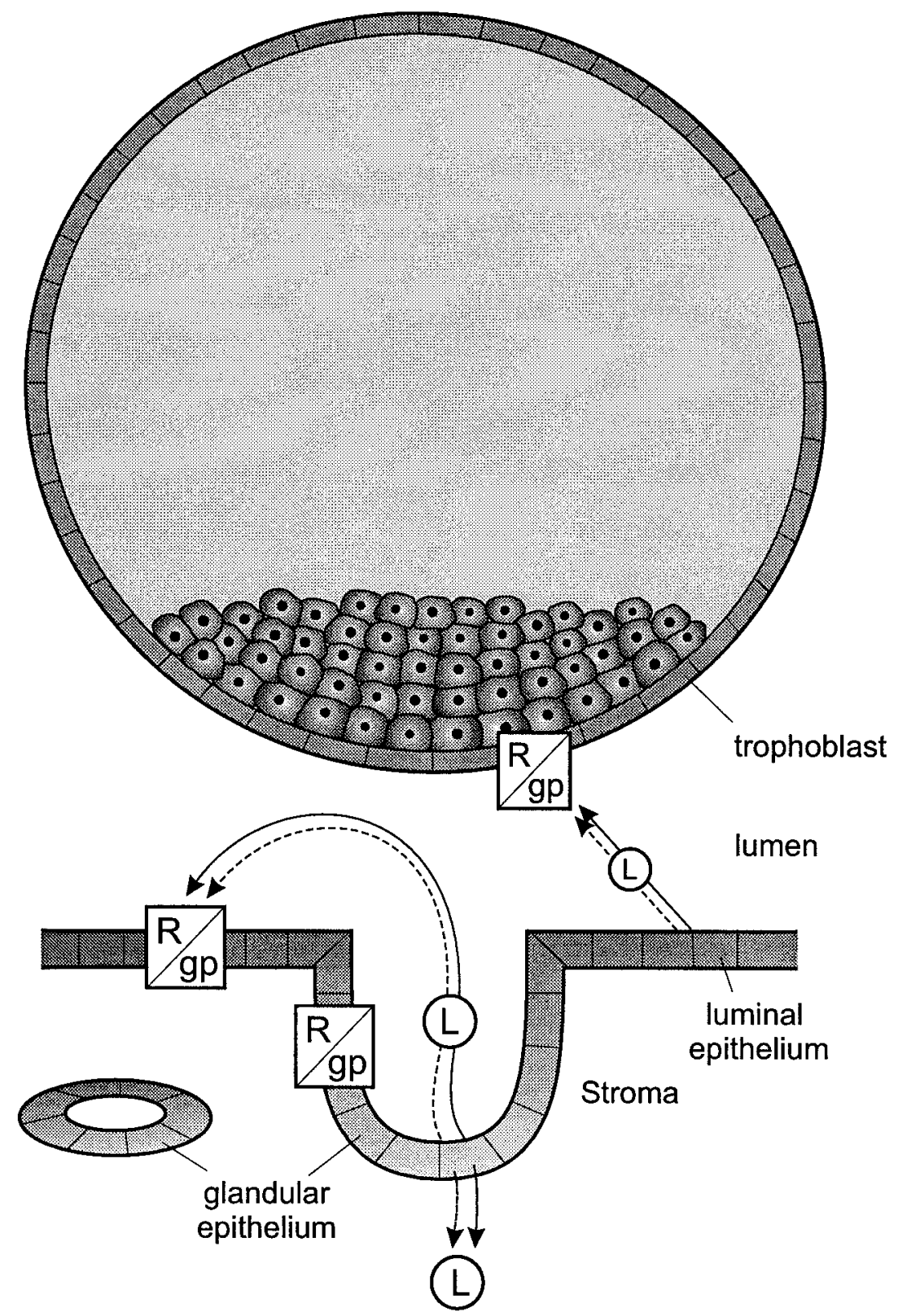

Figure 3 Potential sites of action of LIF at the embryo-endometrial interface. LIF may exert proliferative and/or differentiative actions on a number of cell types in the human uterus, as indicated. LIF may be secreted from glandular epithelium, apically, thus exerting a paracrine action on the luminal epithelium or on the cells of the trophoblast. LIF may also be secreted basally from the epithelium and exert effects on the stroma or on migratory cells within the tissue. L within circle, LIF; R/gp within box, LIFR/gp130 complex; solid line/arrow, proliferation; dotted line/arrow, differentiation.

\section{Limitations of studies to date}

Like many cytokines, LIF appears to be a potential product of many cells following stimulation with suitable inductive signals including E. coli, lipopolysaccharide (Stahl et al. 1990, Brown et al. 1994) and other cytokines (Allan et al. 1990, Campbell et al. 1993, Hamilton et al. 1993). LIF also has the ability to induce the expression of cytokines as well 
as other regulatory molecules in vitro (Richards et al. 1993, Villiger et al. 1993, Harvey et al. 1995). A general problem which complicates experiments utilising any cells in vitro is that the expression of many growth factors and cytokines, including LIF, increase after a few hours in culture (Arici et al. 1995) confounding the results of such studies. The potential interaction of cytokines and the cell types within the local endometrial environment requires investigation, and in vitro studies, although unable to imitate the in vivo environment completely, may give some indication of how certain factors including LIF interact.

The development of transgenic mice has significantly enhanced our understanding of how certain genes function during early pregnancy. However, such mice harbour null mutations in all cell types throughout development and adulthood. Recent advances in gene knockout technology have been described which unlike conventional techniques impose tissue or cell type specific genetic deletions, and progress towards temporal restrictions is under way (Tsien et al. 1996). Such approaches will further enhance our knowledge and understanding of the factors critical for early pregnancy. However, given the variability in the process of embryo implantation between species, there is still an urgent need for functional studies on the role of LIF in the establishment of pregnancy in a primate model.

\section{Conclusions}

Systematic studies of the cellular and biological changes that take place in the embryo-endometrial axis are still required to understand the mechanisms involved in endometrial function and blastocyst implantation. It is anticipated that when the mechanisms underlying normal embryonic and endometrial development are elucidated, fertility and infertility will be more precisely understood and hence able to be effectively controlled.

LIF participates in and is predicted to be a key component in the initiation and maintenance of early pregnancy. LIF is required for blastocyst implantation in mice and may have widespread importance during early pregnancy in other mammalian species. Uterine LIF expression in species other than the mouse confirms that LIF is not necessarily confined to the day of blastocyst implantation; this may be due to the absence of a nidatory pulse of oestradiol in the other mammalian species investigated. Thus, LIF may have additional functions around the time of implantation or expected implantation which have not yet been fully investigated.

The endometrium is rapidly and continually remodelling tissue responding to steroid hormones and locally produced growth factors and cytokines throughout the menstrual cycle and early pregnancy. Much of the in vivo information on LIF in the human has been derived from uterine tissue obtained throughout the menstrual cycle; tissue from early human pregnancy has not been available for study. Additional information suggesting that LIF is an important cytokine during early human pregnancy, arises from recent investigations correlating a decrease in LIF production with women suffering from unexplained infertility. If this proves to be correct, LIF may potentially be used as a therapeutic agent to treat fertility failure related to implantation. Recombinant human LIF (AM424) has been reported in clinical trials (Kurek et al. 1998) making this a testable hypothesis. Furthermore, in vitro studies indicate that LIF is also involved in the cell-to-cell communication at the decidual-trophoblast interface.

A large number of cytokines and other mediators are also expressed in the uterine epithelium and some of these have been demonstrated in vitro to regulate or to be regulated by LIF. Thus, the full and diverse complexity of the interactions between LIF and other mediators of endometrial origin also need to be addressed. This could be investigated by a combination of in vitro studies on endometrial tissue, or in vivo by the targeted disruption of the genes from a number of potentially important mediators. Moreover, blocking the production or action of LIF and other mediators in the adult rather than throughout development (as occurs with transgenic mice), may further elucidate the role of important regulators of endometrial function. Further insights will be obtained from comparative studies as well as from in-depth analysis of individual species and implantation sequences. In addressing such questions an understanding of the regulation of endometrial function and blastocyst implantation at the molecular level should be attainable.

\section{Acknowledgements}

The authors are grateful to the AMRAD Corporation for their support and the provision of biological materials used in their studies.

\section{References}

Ace CI \& Okulicz WC 1995 Differential regulation by estrogen and progesterone in the primate endometrium. Molecular and Cellular Endocrinology 115 95-103.

Allan EH, Hilton DJ, Brown MA, Evely RS, Yumita S, Metcalf D, Gough NM, Ng KW, Nicola NA \& Martin TJ 1990 Osteoblasts display receptors for and responses to leukemia-inhibitory factor. Journal of Cellular Physiology 145 110-119.

Aplin JD 1991 Review: implantation, trophoblast differentiation and hemochorial placentation, mechanistic evidence in vivo and in vitro. Journal of Cell Science 99 681-692.

Arici A, Engin O, Attar E \& Olive D L 1995 Modulation of leukemia inhibitory factor gene expression and protein biosynthesis in human endometrium. Journal of Clinical Endocrinology and Metabolism 80 1908-1914.

Bhatt H, Brunet LJ \& Stewart CL 1991 Uterine expression of leukemia inhibitory factor coincides with the onset of blastocyst implantation. Proceedings of the National Academy of Sciences of the USA 88 11408-11412. 
Brown MA, Metcalf D \& Gough NM 1994 Leukaemia inhibitory factor and interleukin 6 are expressed at very low levels in the normal adult mouse and are induced by inflammation. Cytokine $\mathbf{6}$ 300-309.

Cameron ST, Critchley HOD \& Baird DT 1996 Immunolocalisation of leukaemia inhibitory factor in secretory endometrium after antiprogestins. 4th European Congress on Prostaglandins and Other Locally Active Factors in Reproduction, Stockholm, Sweden, May 22-25, Abstract f5.

Campbell IK, Waring P, Novak U \& Hamilton JA 1993 Production of leukemia inhibitory factor by human articular chondrocytes and cartilage in response to interleukin-1 and tumor necrosis factor $\alpha$. Arthritis Rheumatism 36 790-794.

Charnock-Jones DS, Sharkey AM, Fenwick P \& Smith SK 1994 Leukemia inhibitory factor mRNA concentration peaks in human endometrium at the time of implantation and the blastocyst contains mRNA for the receptor at this time. Journal of Reproduction and Fertility 101 421-426.

Conquet F \& Brulet P 1990 Developmental expression of the myeloid leukemia inhibitory factor gene in preimplantation blastocysts and in extraembryonic tissue of mouse embryos. Molecular and Cellular Biology 10 3801-3805.

Cullinan EB, Abbondanzo SJ, Anderson PS, Pollard JW, Lessey BA \& Stewart CL 1996 Leukemia inhibitor factor (LIF) and LIF receptor expression in human endometrium suggests a potential autocrine/ paracrine function in regulating embryo implantation. Proceedings of the National Academy of Sciences of the USA 93 3115-3120.

Davis S, Aldrich TH, Stahl N, Pan L, Taga T, Kishomoto T, Ip N \& Yancopoulos GD 1993 LIFR $\beta$ and gp130 as heterodimerizing signal transducers of the tripartite CNTF receptor. Science $\mathbf{2 6 0}$ 1805-1808.

De Feco VJ 1967 Decidualization. In Cellular Biology of the Uterus, pp 191-290. Ed RM Wynn. New York: Appleton-Century-Crofts.

Delage G, Moreau JF, Taupin JL, Freitas S, Hambartsoumian E, Olivennes F, Fanchin R, Letur-Konirsch H, Frydman R \& Chaouat G 1995 In vivo endometrial secretion of human interleukin for DA cells/leukaemia inhibitory factor by explant cultures from fertile and infertile women. Human Reproduction $\mathbf{1 0}$ 2483-2488.

Dunglison GF, Barlow DH \& Sargent IL 1996 Leukaemia inhibitory factor significantly enhances the blastocyst formation rates of human embryos cultured in serum-free medium. Human Reproduction 11 191-196.

Enders AC, Schlafke S \& Welsh AO 1980 Trophoblastic and uterine luminal epithelial surfaces at the time of blastocyst adhesion in the rat. American Journal of Anatomy 159 59-72.

Escary J-L, Perreau J, Dumenil D, Ezine S \& Brulet P 1993 Leukaemia inhibitory factor is necessary for maintenance of haematopoietic stem cells and thymocyte stimulation. Nature 363 361-364.

Falck Larson J 1980 Human implantation and clinical aspects. Progress in Reproductive Biology 7 284-296.

Finn CA 1986 Implantation, menstruation and inflammation. Biological Reviews 61 313-328.

Finn CA \& McLaren A 1967 A study of the early stages of implantation. Journal of Reproduction and Fertility 13 259-267.

Fry RC, Batt PA, Fairclough RJ \& Parr RA 1992 Human leukemia inhibitory factor improves the viability of cultured ovine embryos. Biology of Reproduction 46 470-474.

Gearing DP, Gough NM, King JA, Hilton DJ, Nicola NA, Simpson RJ, Nice EC, Kelso A \& Metcalf D 1987 Molecular cloning and expression of cDNA encoding a murine myeloid leukaemia inhibitory factor (LIF). EMBO Journal 6 3995-4002.

Gearing DP, King JA \& Gough NM 1988 Complete sequence of murine myeloid leukaemia inhibitory factor (LIF). Nucleic Acids Research 169857.
Gearing DP, Thut CJ, VandenBos T, Gimpel SD, Delaney PB, King J, Price V, Cosman D \& Beckmann MP 1991 Leukemia inhibitory factor receptor is structurally related to the IL-6 signal transducer, gp130. EMBO Journal 10 2839-2848.

Gearing DP, Comeau MR, Friend DJ, Gimpel SD, Thut CJ, McGourty J, Brasher KK, King JA, Gillis S, Mosley J, Zieger SF \& Cosman D 1992 The IL-6 signal transducer, gp130: an oncostatin receptor and affinity converter for the LIF receptor. Science $\mathbf{2 5 5}$ $1434-1437$.

Gemzell Danielsson K, Swahn ML \& Bygdeman 1997 The effect of various doses of mifepristone on endometrial leukaemia inhibitory factor expression in the midluteal phase - an immunohistochemical study. Human Reproduction 12 1293-1297.

Giudice LC \& Saleh W 1994 Growth factors in reproduction. TEM 6 60-69.

Gough NM, Willson TA, Stahl J \& Brown MA 1992 Molecular biology of the leukemia inhibitory factor gene. In Polyfunctional Cytokines: IL-6 and LIF, pp 24-46. Ciba Foundation Symposium. Eds GR Bock \& K Widdows. West Sussex: John Wiley \& Sons Ltd.

Guilbert L, Robertson SA \& Wegmann TG 1993 The trophoblast as an integral component of a macrophage-cytokine network. Immunology and Cellular Biology 71 49-57.

Hambartsoumian E 1998 Endometrial leukemia inhibitory factor (LIF) as a possible cause of unexplained infertility and multiple failures of implantation. American Journal of Reproductive Immunology 39 137-143.

Hamilton JA, Waring PA \& Filonzi EL 1993 Induction of leukemia inhibitory factor in human synovial fibroblasts by IL-1 and tumor necrosis factor- $\alpha$. Journal of Immunology 150 1496-1502.

Harvey MB, Leco KJ, Arcellana-Panililo MY, Zhang X, Edwards DR \& Schultz GA 1995 Proteinase expression in early mouse embryos is regulated by leukaemia inhibitory factor. Development $\mathbf{1 2 1}$ 1005-1014.

Hearn J 1980 Primate models for early human pregnancy. In Animal Models in Human Reproduction, pp 319-332. Eds M Serio \& M Martini. New York: Raven Press.

Hearn JP, Webley GE \& Gidley-Baird AA 1991 Chorionic gonadotropin and embryo-maternal recognition during the peri-implantation period in primates. Journal of Reproduction and Fertility 92 497-509.

Hilton DJ 1992 LIF: lots of interesting functions. Trends in Biochemistry and Science 17 72-76.

Hilton DJ, Nicola NA, Gough NM \& Metcalf D 1988a Resolution and purification of three distinct factors produced by Krebs ascites cells which have differentiation-inducing activity on murine myeloid leukaemia cell lines. Journal of Biological Chemistry 263 9238-9243.

Hilton DJ, Nicola NA \& Metcalf D $1988 b$ Purification of a murine leukaemia inhibitory factor from Krebs ascites conditioned cells. Analytical Biochemistry 173 359-367.

Ip NY, Nye SH, Boulton TG, Davis S, Taga T, Li Y, Birren SJ, Yasukawa K, Kishimoto T, Anderson DJ, Stahl N \& Yancopoulos GD 1992 CNTF and LIF act on neuronal cells via shared signaling pathways that involve the IL-6 signal transducing receptor component gp130. Cell 69 1121-1132.

Kojima K, Kanzaki H, Iwai M, Hatayama H, Fujimoto M, Ioue T, Horie K, Nakayama H, Fujita J \& Mori T 1994 Expression of leukemia inhibitory factor in human endometrium and placenta. Biology of Reproduction $\mathbf{5 0} 882-887$.

Kurek JB, Radford AJ, Crump DE, Bower JJ, Feeny SJ, Austin L \& Byrne E 1998 LIF (AM424), a promising growth factor for the treatment of ALS. Journal of the Neurological Sciences (In Press).

Laird SM, Tuckerman EM, Dalton CF, Dunphy BC, Li TC \& Zhang X 1997 The production of leukaemia inhibitory factor by human endometrium: presence in uterine flushings and production by cells in culture. Human Reproduction 12 569-574. 
Liu H-C, Jones GS, Jones HW \& Rosenwaks Z 1988 Mechanisms and factors of early pregnancy wastage in in vitro fertilisationembryo transfer patients. Fertility and Sterility 50 95-101.

Metcalf D 1992 Leukemia inhibitory factor - a puzzling polyfunctional regulator. Growth Factors 7 169-173.

Murakami M, Hibi M, Nakagawa N, Nakagawa T, Yasukawa K, Yamanishi K, Taga T \& Kishimoto T 1993 IL-6 induced homodimerization of gp130 and associated activation of a tyrosine kinase. Science 260 1808-1810.

Murray R, Lee F \& Chi CP 1990 The genes for leukemia inhibitory factor and interleukin 6 are expressed in mouse blastocysts prior to the onset of hemopoiesis. Molecular and Cellular Biology 10 4953-4956.

Nachtigall MJ, Kliman HJ, Feinberg RF, Olive DL, Engin O \& Arici A 1996. The effect of leukaemia inhibitory factor (LIF) on trophoblast differentiation: a potential role in human implantation. Journal of Clinical Endocrinology and Metabolism 81 801-806.

Nicola NA \& Metcalf D 1991 Subunit promiscuity among hemopoietic growth factor receptors. Cell 67 1-4.

Orsini MW \& McLaren A 1967 Loss of the zona pellucida in mice, and the effect of tubal ligation and ovariectomy. Journal of Reproduction and Fertility 13 485-499.

Parr MB \& Parr EL 1989 The implantation reaction. In Biology of the Uterus, pp 233-277. Eds RM Wynn \& WP Jollie. New York and London: Plenum Medical Book Company.

Pennica D, Shaw KJ, Swanson TA, Moore MW, Shelton DL, Zioncheck KA, Rosenthal A, Taga T, Paoni NF \& Wood WI 1995 Cardiotrophin-1. Biological activities and binding to the leukemia inhibitory factor/gp130 signaling complex. Journal of Biological Chemistry 270 10915-10922.

Perry JS 1981 The mammalian fetal membranes. Journal of Reproduction and Fertility 62 321-335.

Richards CD, Shoyab M, Brown TJ \& Gauldie J 1993 Selective regulation of metalloproteinase inhibitor (TIMP-1) by oncostatin M in fibroblasts in culture. Journal of Immunology 150 5596-5603.

Robertson SA, Lavranos TC \& Seamark RF 1991 In vitro models of the maternal-fetal interface. In Molecular and Cellular Immunobiology of the Maternal Fetal Interface, pp 191-206. Eds TG Wegmann, TG Gill III \& E Nisbet-Brown. New York: Oxford University Press.

Rowson LEA \& Moor RM 1966 The corpus luteum of the sheep: effect of the removal of embryos on luteal function. Journal of Endocrinology 34 497-502.

Salamonsen LA \& Woolley DE 1996 Matrix metalloproteinases and their tissue inhibitors in endometrial remodelling and menstruation. Reproduction and Medical Reviews 5 185-203.

Salamonsen LA, Young RJ, Garcia S \& Findlay JK 1997 Mitogenic actions of endothelin and other growth factors in ovine endometrium. Journal of Endocrinology 152 283-290.

Sawai K, Matsuzaki N, Kameda T, Hashimoto K, Okada T, Shimoya K, Nobunaga T, Taga T, Kishimoto T \& Saji F 1995 Leukemia inhibitory factor produced at the fetomaternal interface stimulates chorionic gonadotropin production: its possible implication during pregnancy, including implantation period. Journal of Clinical Endocrinology and Metabolism 80 1449-1456.

Sawai K, Matsuzaki N, Okada T, Shimoya K, Koyama M, Azuma C, Saji F \& Murata Y 1997 Human decidual cell biosynthesis of leukemia inhibitory factor: regulation by decidual cytokines and steroid hormones. Biology of Reproduction 56 1274-1280.

Senturk LM \& Arici A 1998 Leukemia inhibitory factor in human reproduction. American Journal of Reproductive Immunology 39 144-151.

Shen MM \& Leder P 1992 Leukemia inhibitory factor is expressed by the preimplantation uterus and selectively blocks primitive ectoderm formation in vitro. Proceedings of the National Academy of Sciences of the USA 89 8240-8244.

Smart YC, Fraser LS, Roberts TK, Clancy RL \& Cripps AW 1982 Fertilization and early pregnancy loss in healthy women attempting conception. Clinical Reproduction and Fertility 1 177-184.
Smith AG, Heath JK, Donaldson DD, Wong GG, Moreau J, Stahl M \& Rogers D 1988 Inhibition of pluripotential embryonic stem cell differentiation by purified polypeptides. Nature 336 688-690.

Stahl J, Gearing DP, Willson TA, Brown MA, King JA \& Gough MN 1990 Structural organization of the genes for murine and human leukemia inhibitory factor. Journal of Biological Chemistry 265 8833-8841.

Stahl N \& Yancopoulos GD 1993 The alphas, betas and kinases of cytokine receptor complexes. Cell 74 587-590.

Stewart CL 1994 Leukaemia inhibitory factor and the regulation of pre-implantation development of the mammalian embryo. Molecular Reproduction and Development 39 233-238.

Stewart CL \& Cullinan E B 1997 Preimplantation development of the mammalian embryo and its regulation by growth factors. Developmental Genetics 21 91-101.

Stewart CL, Kaspar P, Brunet LJ, Bhatt H, Gadi I, Kontgen F \& Abbondanzo ST 1992 Blastocyst implantation depends on maternal expression of leukaemia inhibitory factor. Nature 359 76-79.

Tabibzadeh S 1991 Human endometrium: an active site of cytokine production and action. Endocrine Reviews 12 272-290.

Taga T \& Kishimoto T 1992 Cytokine receptors and signal transduction. FASEB Journal 6 3387-3396.

Tomida M, Yamamoto-Yamaguchi Y \& Hozumi M 1984 Purification of a factor inducing differentiation of mouse myeloid leukaemic M1 cells from conditional medium of mouse fibroblast L929 cells. Journal of Biological Chemistry 259 10978-10982.

Tsien JZ, Feng Chen D, Gerber D, Tom C, Mercer ER, Anderson DJ, Mayford M, Kandel ER \& Tonegawa S 1996 Subregion and cell type restricted gene knockout in mouse brain. Cell $\mathbf{8 7}$ 1317-1326.

Villiger PM, Geng Y \& Lotz M 1993 Induction of cytokine expression by leukemia inhibitory factor. Journal of Clinical Investigation 91 1575-1581.

Vogiagis D, Marsh MM, Fry RC \& Salamonsen LA 1996 Leukaemia inhibitory factor in human endometrium throughout the menstrual cycle. Journal of Endocrinology 148 95-102.

Vogiagis D, Fry RC, Sandeman RM \& Salamonsen LA 1997 a Leukaemia inhibitory factor in ovine endometrium during the oestrous cycle and early pregnancy. Journal of Reproduction and Fertility 109 279-288.

Vogiagis D, Salamonsen LA, Sandeman RM, Squires TJ, Butt AR \& Fry RC 1997b Passive immunisation of ewes against leukaemia inhibitory factor during early pregnancy. Reproduction, Nutrition and Development 37 459-468.

Ware CB, Horowitz MC, Renshaw BR, Hunt JS, Liggitt D, Koblar SA, Gliniak B C, McKenna HJ, Papaynnopoulou T, Thoma B, Cheng L, Donovan PJ, Peschon JJ, Bartlett PF, Willis CR, Wright BD, Carpenter MK, Davidson BL \& Gearing DP 1995 Targeted disruption of the low-affinity leukemia inhibitory factor receptor gene causes placental, skeletal, neural and metabolic defects and results in perinatal death. Development 121 1283-1299.

Williams RL, Hilton DJ, Pease S, Willson TA, Stewart CL, Gearing DP, Wagner EF, Metcalf D, Nicola NA \& Gough NM 1988 Myeloid leukemia inhibitory factor maintains the developmental potential of embryonic stem cells. Nature 336 684-687.

Wooding FBP \& Flint APF 1994 Placentation. In Marshall's Physiology of Reproduction 4th ed. Pregnancy and Lactation, Part 1: Ovulation and Early Pregnancy, pp 235-429. Ed GE Lamming. London: Chapman \& Hall.

Yang Z-M, Le S-P, Chen D-B \& Harper MJK 1994 Temporal and spatial expression of leukemia inhibitory factor in rabbit uterus during early pregnancy. Molecular and Reproductive Development 38 148-152.

Yang Z-M, Chen D-B, Le S-P \& Harper MJK 1996 Differential hormonal regulation of leukemia inhibitory factor (LIF) in rabbit and mouse uterus. Molecular and Reproductive Development $\mathbf{4 3}$ $470-476$. 
Yoshida K, Taga T, Saito M, Suematsu S, Kumanogoh A, Tanaka T, Fujiwara H, Hirata M, Yamagami T, Nakahata T, Hirabayashi T, Yoneda Y, Tanaka K, Wang W-Z, Mori C, Shiota K, Yoshida N \& Kishimoto T 1996 Targeted disruption of gp130, a common signal transducer for the interleukin 6 family of cytokines, leads to myocardial and haematological disorders. Proceedings of the National Academy of Sciences of the USA 93 407-411.
Zhang JG, Owczarek CM, Ward LD, Howlett GJ, Fabri LJ, Roberts BA \& Nicola NA 1997 Evidence for the formation of a heterotrimeric complex of leukaemia inhibitory factor with its receptor subunits in solution. Biochemistry Journal 325 693-700.

Received 29 June 1998

Accepted 27 August 1998 